\title{
A Cytochrome P450 Gene Is Differentially Expressed in Compatible and Incompatible Interactions Between Pepper (Capsicum annuum) and the Anthracnose Fungus, Colletotrichum gloeosporioides
}

\author{
Boung-Jun Oh, Moon Kyung Ko, Young Soon Kim, Kwang Sang Kim, Igor Kostenyuk, \\ and Hye Kyung Kee \\ Kumho Life and Environmental Science Laboratory, Korea Kumho Petrochemical Co., Ltd., 1 Oryong-Dong, \\ Puk-Ku, Kwangju 500-712, Korea \\ Accepted 31 August 1999.
}

The anthracnose fungus, Colletotrichum gloeosporioides, was previously shown to have an incompatible interaction with ripe-red fruit of pepper (Capsicum annuum). However, the fungus had a compatible interaction with unripemature-green fruit. Using mRNA differential display, we isolated and characterized a $P$ epCYP gene expressed in the incompatible interaction. The $P$ epCYP gene encodes a protein homologous to cytochrome $\mathbf{P 4 5 0}$ proteins containing a heme-binding domain. The expression level of PepCYP is higher in the incompatible interaction than in the compatible interaction, and then remains elevated in the incompatible interaction. In the compatible interaction, the expression of PepCYP is transient. The induction of Pep$C Y P$ gene is up-regulated by wounding or jasmonic acid treatment during ripening. Analysis of PepCYP expression by in situ hybridization shows that the accumulation of PepCYP mRNA is localized in the epidermal cell layers, but not in the cortical cell layers. An examination of transverse sections of the fruits inoculated with the fungus shows that the fungus invades and colonizes the epidermal cell layers of the unripe fruit at 24 and $72 \mathrm{~h}$ after inoculation, respectively, but not those of the ripe fruit. These results suggest that the $P e p C Y P$ gene product plays a role in the defense mechanism when the fungus invades and colonizes the epidermal cells of fruits in the incompatible interaction during the early fungal infection process.

Additional keywords: appressorium, biotic stresses, nonclimacteric fruits.

Colletotrichum gloeosporioides (Penz.) Penz \& Sacc. in Penz. is the casual agent of anthracnose diseases on fruit crops (Daykin 1984; Dodd et al. 1991; Prusky et al. 1991) such as

Corresponding author: Boung-Jun Oh; E-mail: bjoh@ksc.kumho.co.kr

Present address of I. Kostenyuk: University of Florida, Citrus Research and Education Center, 700 Experiment Station Road, Lake Alfred 33850-2299, U.S.A.

Nucleotide and/or amino acid sequence data are to be found at the GenBank data base as accession number AF122821. pepper (Capsicum annuum L.) (Kim et al. 1986; Manandhar et al. 1995). Infection caused by $C$. gloeosporioides is achieved through conidium germination and appressorium and infection hypha formation that are necessary for subsequent cuticular penetration (Bailey et al. 1992). In the avocado-C. gloeosporioides interaction, conidium germination and appressorium formation were similar on both unripe-resistant and ripesusceptible fruits (Prusky and Saka 1989; Prusky et al. 1991). In the pepper and $C$. capsici pathosystem, germination and appressorium formation were higher on the unripe-resistant pepper fruit than on the ripe-susceptible fruit (Adikaram et al. 1983). The germination of C. musae was similar on both ripesusceptible and unripe-resistant banana fruits, but appressorium formation was stimulated on the unripe fruit (Swinburne 1976). Taken together, in these pathosystems, although conidium germination and appressorium formation are prerequisites to infection of the host plant, they may not be important factors in determining resistant or susceptible interactions between the host fruit of pre- or post-ripening stages and the Colletotrichum fungus. In contrast, plant responses to fungal morphogenesis during fruit ripening may be more important in determining resistant or susceptible interactions.

In Colletotrichum fungi, the topography of the plant surface was thought to be a physical signal for inducing appressorium formation (Staples and Macko 1980). The surface wax of avocado fruit was reported to act as a chemical signal for appressorium formation in C. gloeosporioides (Podila et al. 1993). In addition, the genes expressed during the appressorium formation of $C$. gloeosporioides induced by the host surface wax were cloned (Hwang and Kolattukudy 1995). However, plant responses to the conidium germination and appressorium formation of $C$. gloeosporioides have not been studied.

In a previous study, we found that an isolate of $C$. gloeosporioides showed an incompatible interaction with the ripe-red pepper fruit and a compatible interaction with the unripe-mature-green fruit (Oh et al. 1998), even though ripe fruits are generally susceptible to pathogen infection (Prusky et al. 1991; Swinburne 1983). In this pathosystem, higher levels of appressorium and infection hypha formation, and longer infection hypha, were observed on the unripe fruit than on the ripe fruit in the early fungal infection step (Kim et al. 1999). 
A typical, sunken necrosis was detected in the unripe fruit, but not in the ripe fruit, at 5 days after inoculation. Based on these data of fungal morphogenesis and symptom development, we studied the gene expression in the pepper-C. gloeosporioides interaction.

Using an mRNA differential display method, we isolated several cDNAs that are differentially induced in the ripe fruit but not in the unripe fruit after fungal infection. In this study, we report the characterization of one of these cDNAs encoding cytochrome $\mathrm{P} 450$ protein $($ PepCYP). To our knowledge, $P e p C Y P$ is the first cytochrome $\mathrm{P} 450$ gene that accumulates to high levels in an incompatible plant-fungus interaction. The expression of the PepCYP gene was examined based on fungal behavior in the initial infection process and on symptom development during the differential interactions. We found that the $P e p C Y P$ gene is induced by wounding or exogenous jasmonic acid (JA) during ripening. A possible role of Pep$C Y P$ in pepper fruits against pathogen infection during ripening is proposed.

\section{RESULTS}

\section{Cloning of a fungal-inducible cytochrome $\mathbf{P 4 5 0}$ gene of pepper.}

To isolate genes differentially induced from the ripe fruit but not from the unripe fruit in response to the fungal infection, we used mRNA differential display (Liang and Pardee 1992). Differential display was performed with total RNAs prepared from both unripe and ripe fruits at 24 and $48 \mathrm{~h}$ after fungal inoculation. The cDNAs amplified from the ripe fruit were excised from the gel, re-amplified, and cloned. RNA gel blot analysis with these clones was performed to confirm their differential expression. A cDNA clone, named pddICC6 for the incompatible Capsicum annuum/Colletotrichum gloeosporioides interaction, hybridized to a transcript of $1.8 \mathrm{~kb}$ that accumulated to high levels in the incompatible interaction (data not shown).

To isolate the full-length cDNA clone, the insert of pddICC6 was used as a probe for plaque hybridization with a cDNA library prepared from mRNA extracted from the unripe fruit at 24 and $48 \mathrm{~h}$ after inoculation (HAI) with the fungus. A clone containing the longest insert from cDNA library screening was designated pICC6, isolated, and sequenced. The 3' region of the pICC6 clone contained the nucleotide sequence of pddICC6 as expected.

\section{Sequence analysis and characterization of PepCYP cDNA.}

The 1,781-bp, full-length sequence (Fig. 1) contains one open reading frame of $1,506 \mathrm{bp}$ from the first translation start
(ATG) at nucleotide position 4 to a translational stop (TGA) at position 1509 (GenBank accession no. AF122821). The nucleotide sequences of pICC6 encode a polypeptide of 502 amino acids with a calculated molecular mass of $56.8 \mathrm{kDa}$. A putative polyadenylation site was identified at 22 bp downstream of the stop codon. The amino acid sequence of this cDNA is highly homologous to the genes encoding cytochrome P450s found in plants. Therefore, the pICC6 clone was designated PepCYP for pepper cytochrome $\underline{\mathrm{P}} 450$. The PepCYP protein contains a hydrophobic membrane anchor region in the $\mathrm{N}$ terminal region (amino acid residues 1 to 27) (Bozak et al. 1990) (Fig. 2). A heme-binding domain (residues 435 to 440), PFGXGXRXCXG, is located in the C terminal region of the polypeptide (Frey et al. 1995).

The highest level of sequence identity was $59 \%$ with a potato cytochrome P450 protein (CYPs.ch) from a Solanum chacoense line rich in glycoalkaloids (Hutvágner et al. 1997) (Fig. 2). Sequence identity was 52 and $48 \%$ with CYP71D8 and CYP71D9 from soybean treated with an elicitor, respectively (Schopfer and Ebel 1998). The identities with other CYP71 subfamilies were $46 \%$ with avocado CYP71A1 (Bozak et al. 1990), 41\% with catmint CYP71A5 (Clark et al. 1997), and 40\% with Arabidopsis CYP71B6 (Mizutani et al. 1998). The minimum identity of amino acid sequence required to assign a cytochrome $\mathrm{P} 450$ within the same family should be higher than 40\% (Nebert et al. 1991). Thus, the pepper gene belongs to the CYP71 family. In the tobacco and phytopathogenic bacterium Pseudomonas solanacearum interaction, the first cytochrome P450 gene hsr515 of tobacco that was expressed during the hypersensitive reaction was isolated (Czernic et al. 1996). The hsr515 protein shared 36\% identity with PepCYP.

\section{Fruit-specific induction of the PepCYP gene by fungal inoculation: Up-regulation during ripening, and upon wounding and JA treatments.}

C. gloeosporioides causes anthracnose diseases on the fruit of various plant species (Daykin 1984; Dodd et al. 1991; Kim et al. 1986, Manandhar et al. 1995, Prusky et al. 1991). Thus, we examined whether the expression of the PepCYP gene was fruit specific by fungal infection or inducible by other treatments. RNA gel blot analysis was performed with total RNAs prepared from fruits, leaves, stems, and roots of the pepper plants at $24 \mathrm{~h}$ after fungal inoculation or wounding. The expression of the PepCYP gene was observed in fruits but not in leaves, stems, or roots after treatments (Fig. 3A). Interestingly, the PepCYP mRNA was induced in both ripe and unripe fruits by fungal infection, but wounding caused the induction of this mRNA only in the ripe fruit.

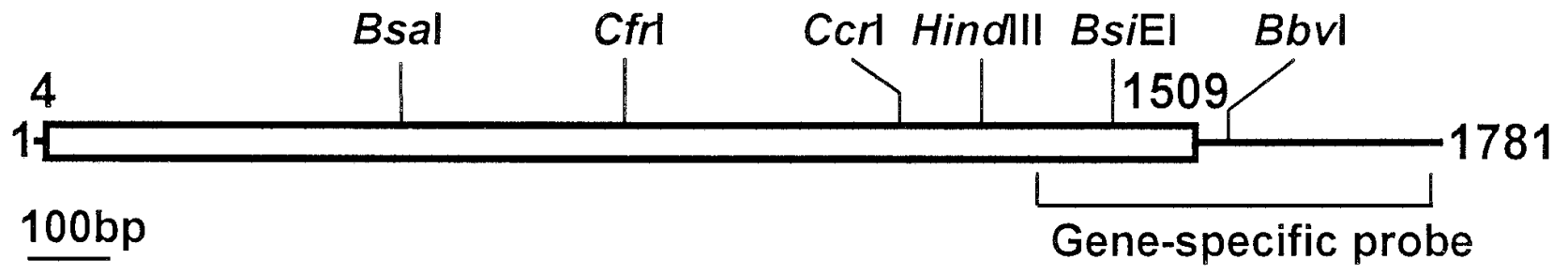

Fig. 1. Restriction enzyme map of a cytochrome P450 cDNA, РерCYP, from pepper (Capsicum апnиum). Numbers indicate nucleotide positions; open bar indicates coding region that is 4 to 1509 nucleotide positions. The $3^{\prime}$ region of the PepCYP clone contains the nucleotide sequence of the cDNA fragment, pddICC6, amplified by differential display. This partial cDNA fragment was used for gene-specific RNA probe for in situ hybridization. 


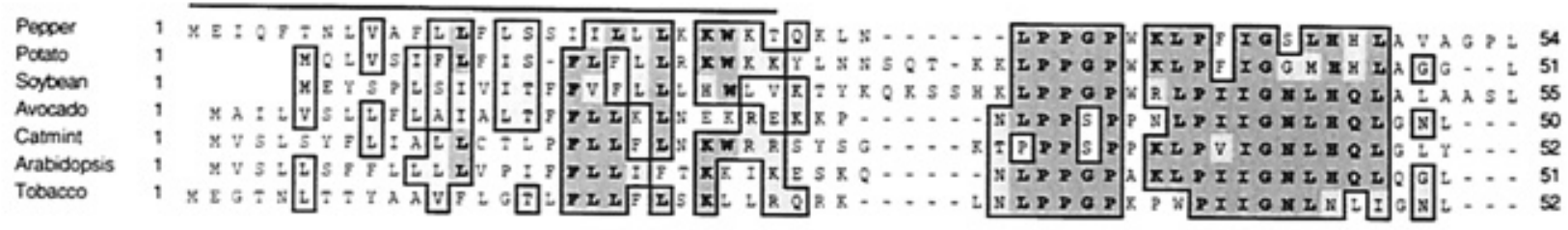

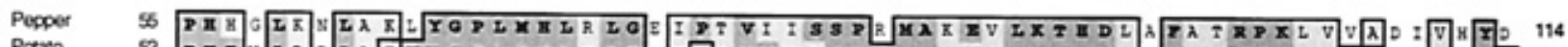

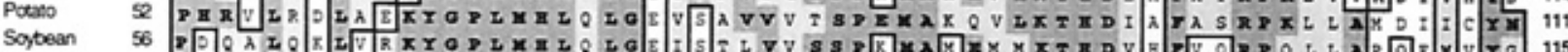

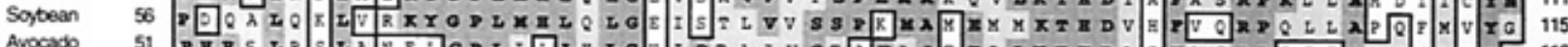

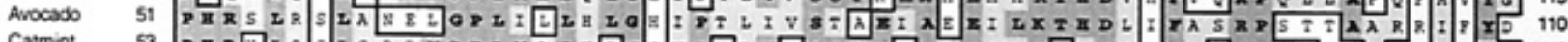

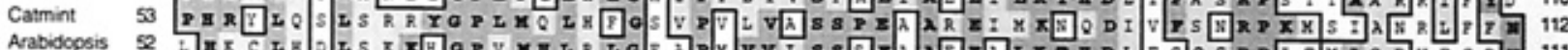

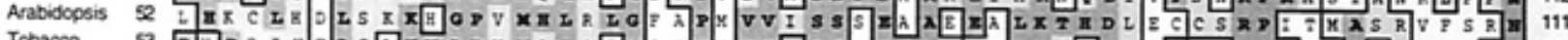

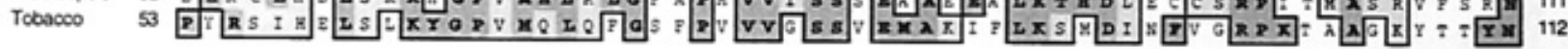

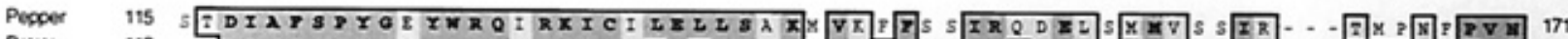

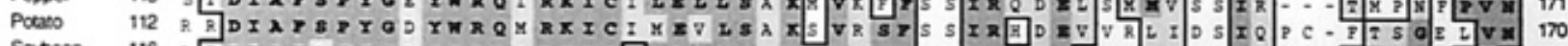

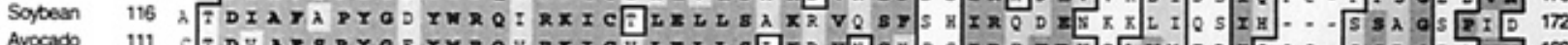

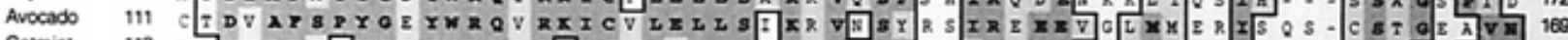

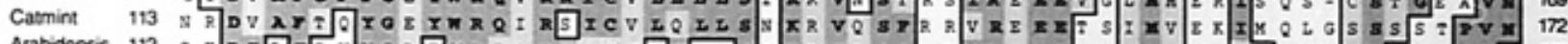

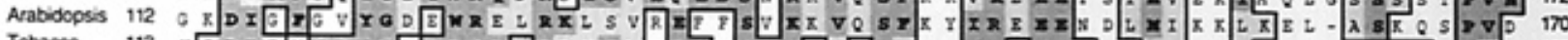

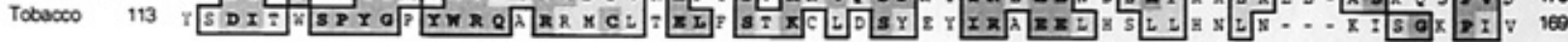

Pepper 172 E:

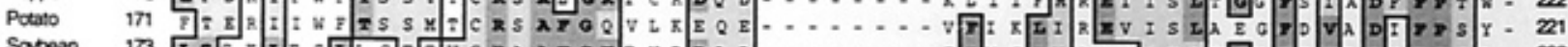

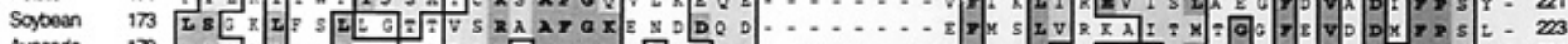

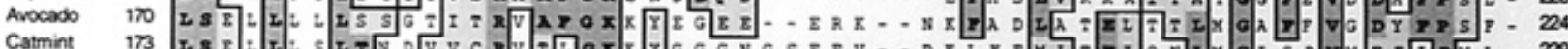

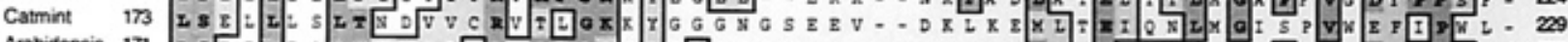

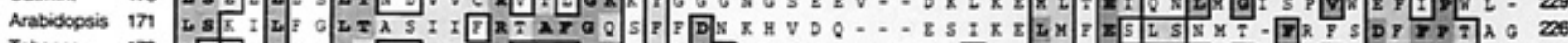

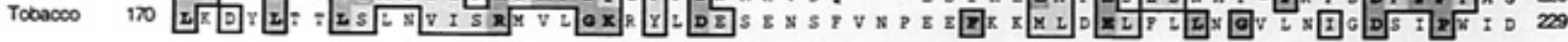

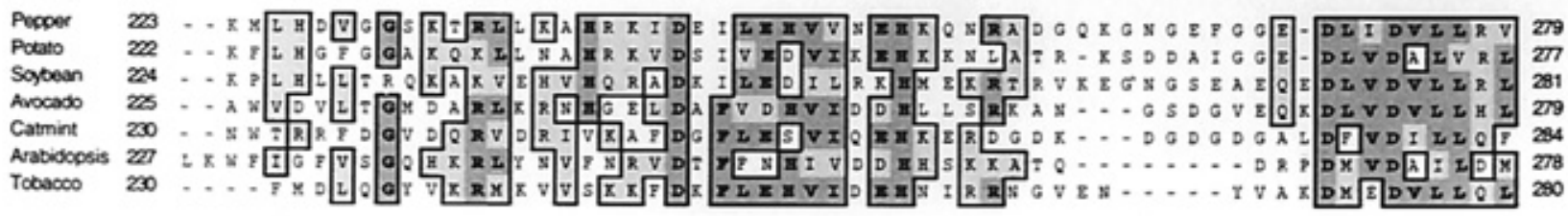

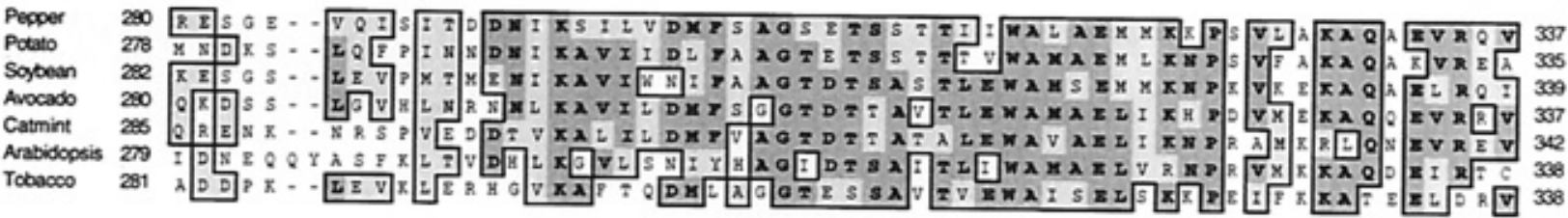

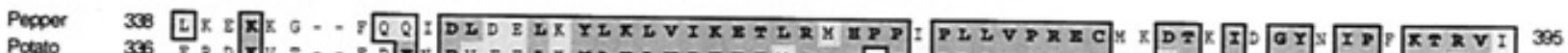

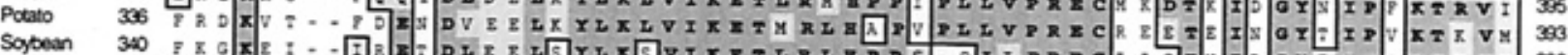

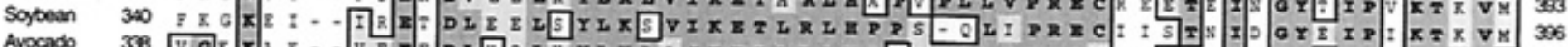

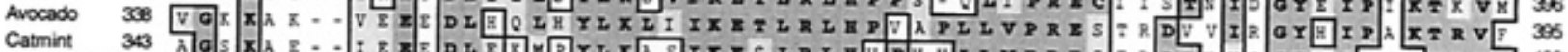

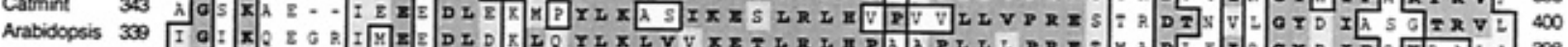

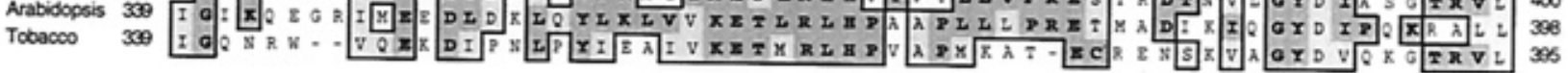

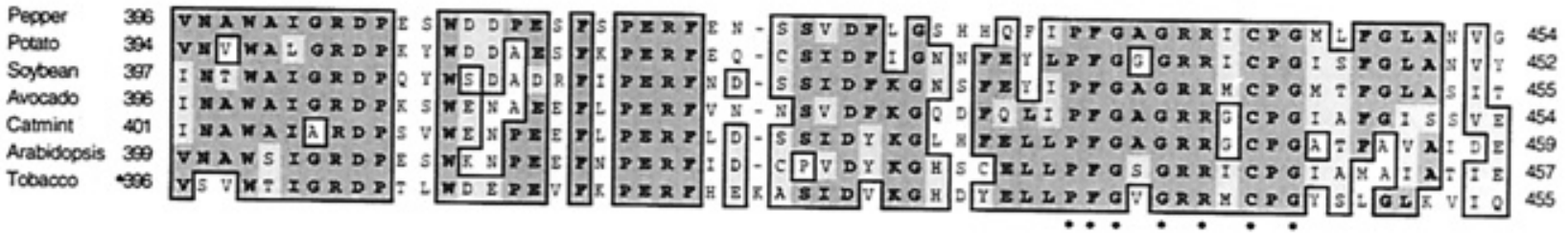

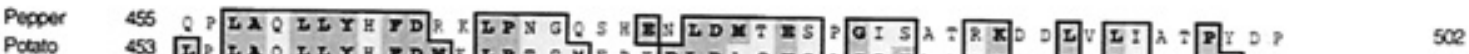

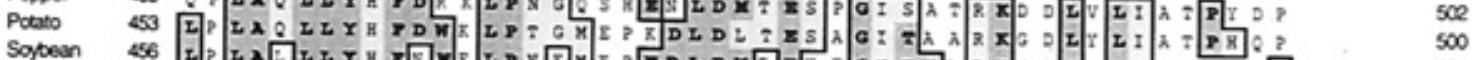

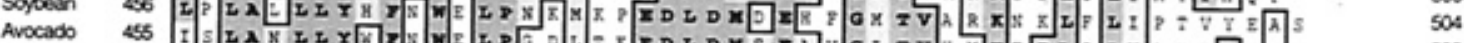

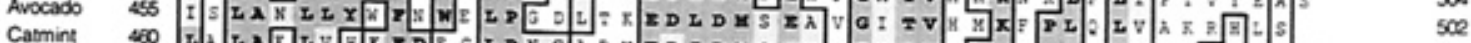

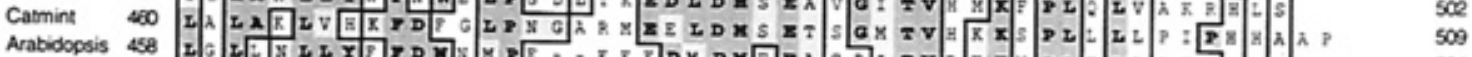

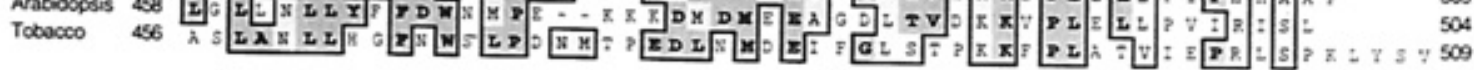


JA is a plant hormone with roles in mechanical wounding responses (Creelman et al. 1992; Creelman and Mullet 1997). Abscisic acid (ABA) is hypothesized to be a key component in the wound-signaling cascade leading to the activation of a defense gene (Peña-Cortés et al. 1996; Wasternack and Partheir 1997). Thus, we further examined whether the wound-inducible Pep$C Y P$ expression is inducible by ABA or JA treatments. RNA gel blot analysis was performed with total RNAs prepared from the application sites of both ripe and unripe fruits drop-applied with ABA or JA for $24 \mathrm{~h}$. PepCYP mRNA highly accumulated only in the ripe fruit treated with JA at $40 \mu \mathrm{M}$ (Fig. 3B). However, ABA did not affect the expression of $P e p C Y P$ in both ripe and unripe fruits. To test whether a high concentration of JA is able to induce the expression of $P e p C Y P$ in the unripe fruit, JA was applied to the unripe fruit at 100,400 , and $1000 \mu \mathrm{M}$. No induction of $P$ epCYP expression was observed in the unripe fruit treated with JA (data not shown).

\section{Differential induction of the PepCYP gene in compatible and incompatible interactions.}

In our previous studies (Kim et al. 1999; Oh et al. 1998), higher levels of appressorium and infection hypha formation were observed on the unripe fruit than on the ripe fruit at 12 and $24 \mathrm{HAI}$, respectively. Initial anthracnose symptoms were detected only on the unripe fruit after $48 \mathrm{HAI}$, and typical sunken necrosis occurred within $120 \mathrm{HAI}$. Thus, we examined whether the induction of time-course of $P e p C Y P$ mRNA by $C$. gloeosporioides inoculation correlated with fungal morphogenesis and symptom development. RNA gel blot analysis was performed with both unripe and ripe fruits at $0,3,6,12$, 24, 48, and 72 HAIs. The PepCYP mRNA was not detected in both ripe and unripe fruits with water inoculation without fungal spores as a control. However, the accumulation of Pep$C Y P$ mRNA was detected in both ripe and unripe fruits from 12 HAI (Fig. 4). In the unripe fruit, expression of the PepCYP gene is transient and peaks at 24 HAI before rapidly declining to barely detectable levels at 48 and 72 HAI. In contrast, in the ripe fruit, the expression level remains elevated. Thus, the results show that the PepCYP gene is inducible by fungal infection and is differentially expressed in compatible and incompatible interactions.

A cDNA for the PR-2 gene from Nicotiana glutinosa was hybridized to the same blots to serve as a molecular marker for the activation of plant defense responses. In the unripe fruit, a basal level of $P R-2 \mathrm{mRNA}$ was not detected, but the accumulation of $P R-2$ mRNA was detected at $12 \mathrm{HAI}$ (Fig. 4), and a biphasic accumulation of $P R-2$ mRNA was observed at 12 and 72 HAIs. In contrast, in the ripe fruit, a basal level of $P R-2$ mRNA was detected. The expression of the $P R-2$ gene was rapidly induced in the ripe fruit at $3 \mathrm{HAI}$ and reached a maximum at $48 \mathrm{HAI}$.

Fig. 2. Alignment of the deduced amino acid sequence from PepCYP cDNA (pepper) (GenBank accession no. AF122821) with other cytochrome P450 proteins from potato (CYPs.ch), soybean (CYP71D8), avocado (CYP71A1), catmint (CYP71A5), Arabidopsis (CYP71B6), and tobacco (hsr515). Upper line indicates hydrophobic N-terminal membrane anchor region of PepCYP (amino acid residues 1 to 27). The conserved PFGXGXRXCXG heme-binding domain in the C-terminal region of the polypeptide is indicated by dots.

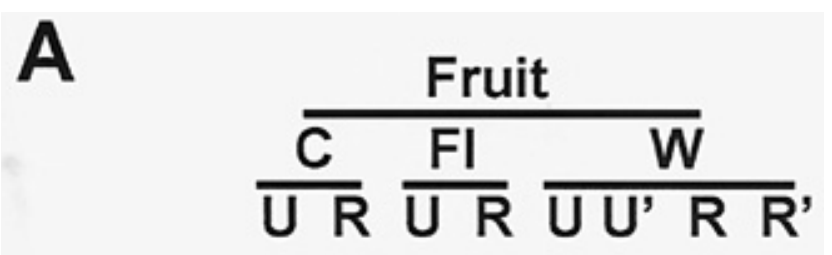

\section{PepCYP}

rRNA
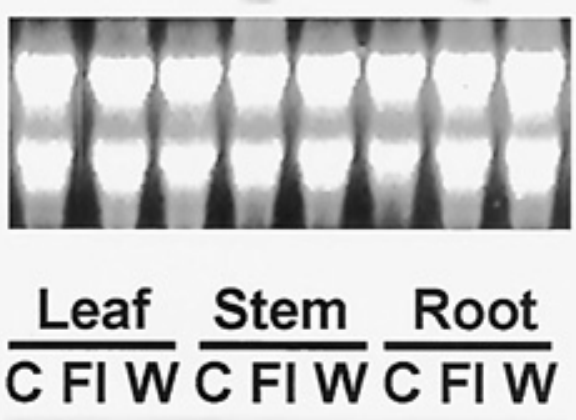

\section{PepCYP}

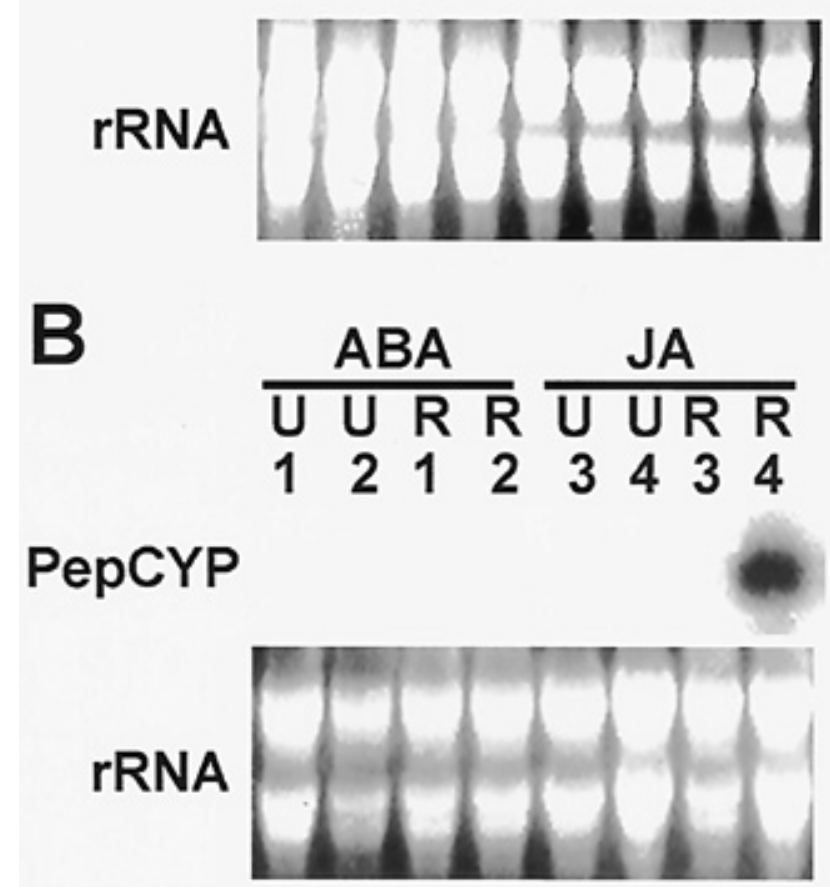

Fig. 3. A, Expression and induction of the PepCYP gene from various organs of pepper by Colletotrichum gloeosporioides inoculation or wounding. RNAs were isolated from the application sites of ripe fruit $(\mathrm{R})$, unripe fruit (U), leaf, stem, and root at $24 \mathrm{~h}$ after the treatments of fungal inoculation (FI) or wounding (W). In addition, RNAs of both ripe $\left(\mathrm{R}^{\prime}\right)$ and unripe fruits $\left(\mathrm{U}^{\prime}\right)$ at $48 \mathrm{~h}$ after wounding were isolated. Ten microliters of $5 \times 10^{5}$ conidia of $C$. gloeosporioides per ml was used for drop inoculation on various pepper organs. Organs treated with $10 \mu \mathrm{l}$ of sterile water except fungal spores for $24 \mathrm{~h}$ were used as the control (C). B, Induction of the PepCYP gene from both ripe and unripe fruits of pepper by exogenous abscisic acid (ABA) or jasmonic acid (JA) treatments. RNAs were isolated from the application sites of both ripe (R) and unripe fruits (U) drop-applied with $10 \mu \mathrm{l}$ of $\mathrm{ABA}(1=4 \mu \mathrm{M}, 2=40$ $\mu \mathrm{M})$ and $\mathrm{JA}(3=4 \mu \mathrm{M}, 4=40 \mu \mathrm{M})$ for $24 \mathrm{~h}$. 
Localization of PepCYP mRNA during early infection.

To examine the localization and accumulation of PepCYP mRNA during early infection, we performed in situ hybridization with a gene-specific antisense or sense RNA probe of pddICC6 (Fig. 1) with sections. The transverse sections were prepared from the infection sites of both ripe and unripe fruits at 24 and 72 HAIs, respectively. The transcript of PepCYP was not detectable in uninoculated unripe (Fig. 5A)

\section{UF/WATER $\quad 0 \quad 3 \quad 6 \quad 12 \quad 244872$ PepCYP}

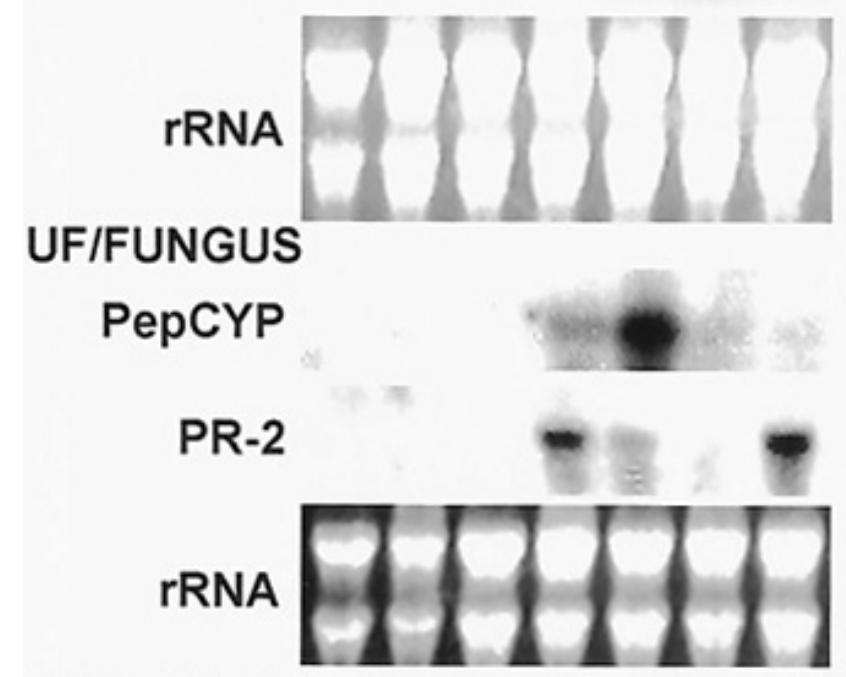

\section{RF/FUNGUS}

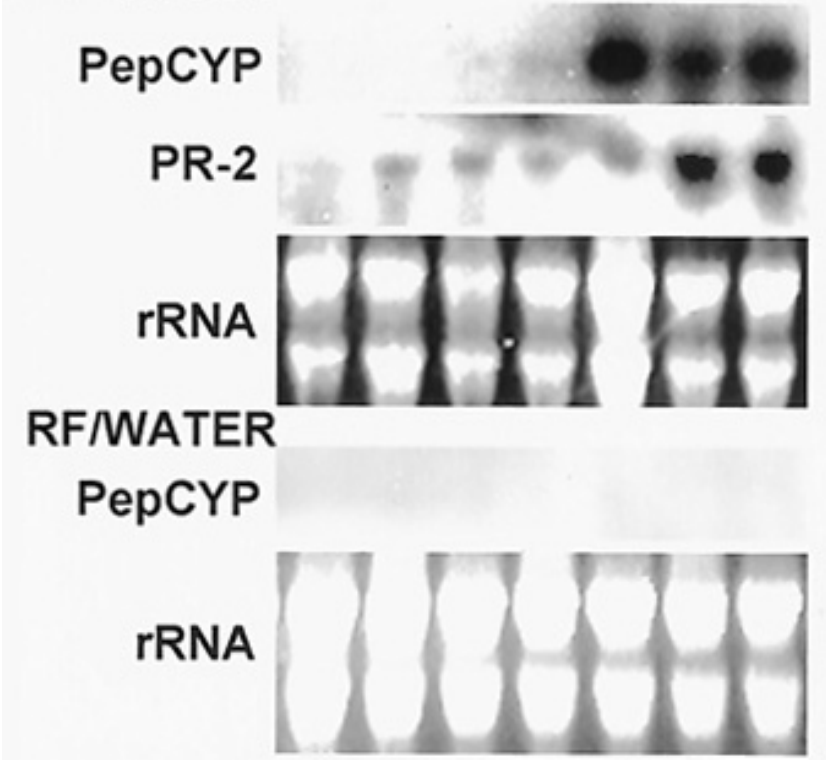

Fig. 4. Differential induction of the $P$ Рер $C Y P$ gene from pepper fruit by Colletotrichum gloeosporioides inoculation. RNAs were isolated from both ripe (RF/FUNGUS - the incompatible interaction) and unripe (UF/FUNGUS - the compatible interaction) fruits after fungal infection with time-course. Water inoculation without fungal spores on both ripe (RF/WATER) and unripe (UF/WATER) fruits was used as the control. A cDNA for the PR-2 gene was hybridized to the same blot. Numbers indicate $\mathrm{h}$ after inoculation. and ripe fruits (Fig. 5D) hybridized with antisense or sense RNA probe (data not shown). In unripe fruit, fungus with infection hypha started to invade outer epidermal cells at 24 HAI (Fig. 5B) (Oh et al. 1998). The accumulation of Pep$C Y P$ mRNA at $24 \mathrm{HAI}$ was localized only in the epidermal cells that were highly vacuolated, and not in the cortical cell layers (Fig. 5B). When the fungus colonized the outer epidermal cells at $72 \mathrm{HAI}$, the induction level of transcripts was very low or undetectable (Fig. 5C). In ripe fruit, fungal invasion was rarely observed at $24 \mathrm{HAI}$ (Fig. 5E), or even at 72 HAI (Fig. 5F). This result shows that fungal invasion and colonization are inhibited in incompatible-ripe fruit during early infection. The accumulation of the transcripts in the epidermal cells at $24 \mathrm{HAI}$ was sustained up to $72 \mathrm{HAI}$. These results suggest that the expression of the PepCYP gene is localized to the epidermal cell layers of the ripe fruit during incompatible interaction.

\section{DISCUSSION}

As a first step to investigate the molecular mechanisms involved in the incompatible interaction between the ripe fruit of pepper and C. gloeosporioides, several cDNAs were isolated that were differentially expressed by fungal infection in the ripe fruit but not in the unripe fruit. In this study, with one of these cDNAs, we showed the characterization of the Pep$C Y P$ gene that encodes a protein homologous to plant cytochrome P450 (Bozak et al. 1990; Frey et al. 1995). Cytochrome P450s in plants are membrane-bound proteins involved in several metabolic pathways related to the defense mechanisms (Maule and Ride 1983; Kessmann et al. 1990). Some genes encoding these proteins are induced by wounding (Batard et al. 1997; Frank et al. 1996). In a plant-phytopathogenic bacterium interaction, the tobacco cytochrome P450 gene, hsr515, was isolated during hypersensitive reaction (Czernic et al. 1996). In this study of a fungal-plant interaction, a pepper cytochrome P450 gene, PepCYP, was differentially expressed in compatible and incompatible interactions. Transcript levels of the two interactions were very different, with maintenance of elevated levels in the incompatible interaction and a very substantial reduction in the compatible interaction. Together with the hsr515 gene in a bacterial-plant interaction, the isolation of $P$ epCYP in the pepper and fungus interaction suggests a new role for cytochrome P450s in plantpathogen interactions.

Sequence comparison showed that PepCYP protein shared highest homology to the CYPs.ch from a Solanum chacoense line rich in glycoalkaloids (Hutvágner et al. 1997) as well as CYP71D8 and CYP71D9 from soybean treated with an elicitor (Schopfer and Ebel 1998). A possible role of CYPs.ch was suggested to be involved in the synthesis of stress-inducible metabolites. CYP71D8 and CYP71D9 may have a variety of functional roles in terpenoid metabolism (Christoffersen et al. 1995). The antimicrobial sesquiterpenoid phytoalexin, capsidol (Chavez-Moctezuma and Lozoya-Gloria 1996; Watson and Brooks 1984), was synthesized in pepper challenged with fungus (Ward 1976) and an abiotic elicitor, UV light (Back et al. 1998). Therefore, these data raise the possibility that PepCYP functions in the pepper plant's defense against fungal infection. The expression of the $P$ epCYP gene in pepper fruit in response to fungal inoculation and wounding (Figs. 3 and 4) 
supports a possible role of PepCYP in the plant's defense mechanism.

The first cytochrome P450, CYP71A, in plants was identified during avocado fruit ripening (Bozak et al. 1990). In this study, a basal level of PepCYP mRNA was not detected in ripe or unripe fruits or other various organs of pepper, and the induction of $P$ ерС $C Y$ was detected only in fruit after fungal inoculation (Fig. 3A). In addition, the expression of PepCYP was induced only in ripe fruit by wounding and JA treatment (Fig. 3A and B). Thus, these results suggest that PepCYP is developmentally and fruit-specifically regulated, and the induction is up-regulated during fruit ripening in response to wounding and JA. JA is reported to have roles in mechanical wounding responses (Creelman et al. 1992; Creelman and

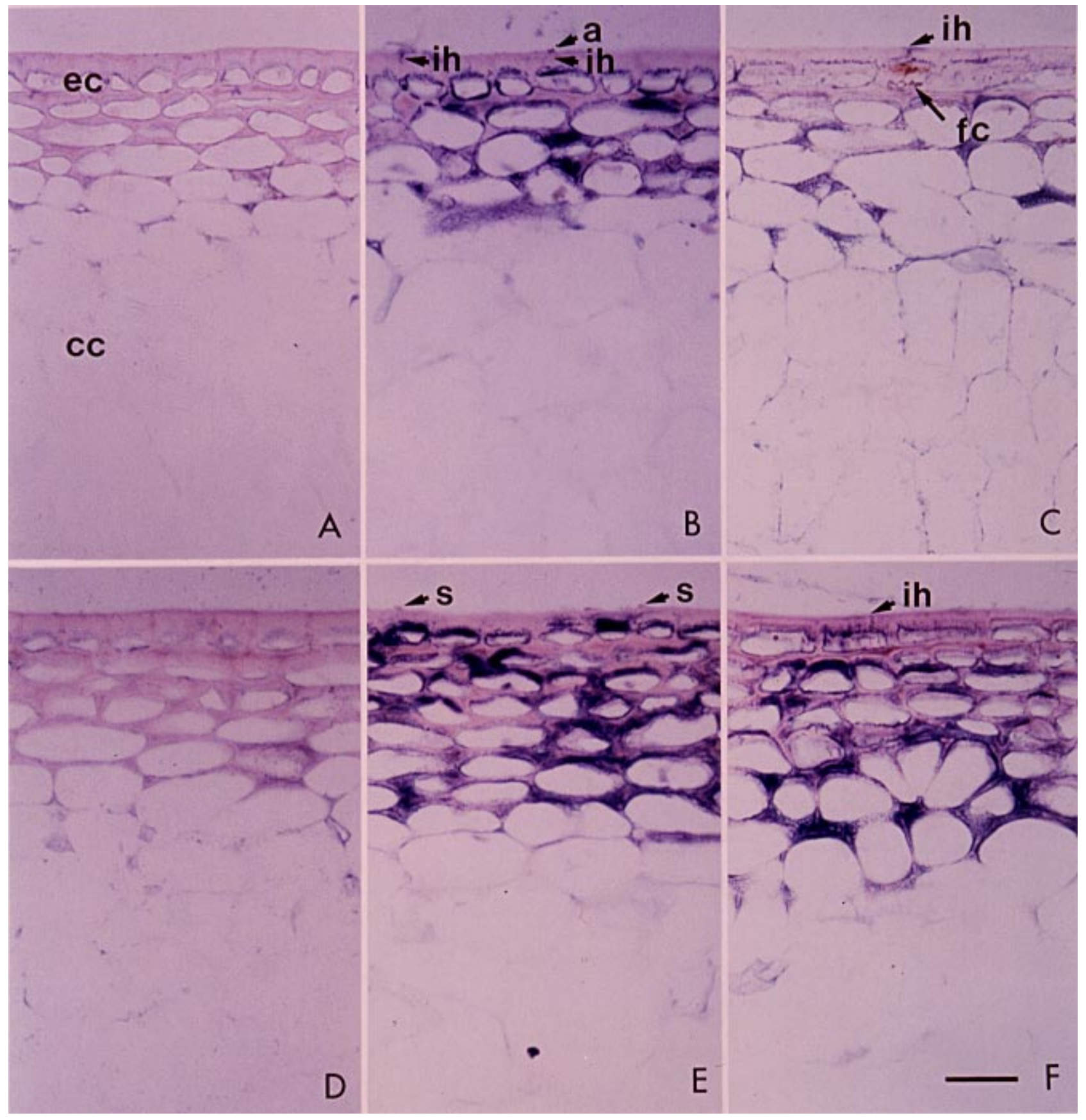

Fig. 5. In situ localization of PepCYP mRNA in pepper fruits at 24 and $72 \mathrm{~h}$ after inoculation (HAI) with Colletotrichum gloeosporioides. The fungus with infection hypha started to invade in the outer epidermal cells of the unripe fruit at (B) 24 HAI, and subsequently (C) colonized the epidermal cells at 72 HAI. However, the fungal invasion was rarely observed in the ripe fruit at (E) 24 and (F) 72 HAIs. Transverse sections were hybridized with the digoxigenin (DIG)-labeled, antisense RNA probe of pddICC6 as a gene-specific probe. In both uninoculated (A) unripe and (D) ripe fruits used for the controls, transcripts were not detected in the epidermal and cortical cell layers. Deep-blue precipitation of transcripts was detected only in the epidermal cell layers (ec) of both (B) unripe and (E) ripe fruits at $24 \mathrm{HAI}$, and of $(\mathbf{F})$ the ripe fruit at $72 \mathrm{HAI}$, but not in the cortical cell layers (cc). Transcripts were not detected in the unripe fruit that was colonized by the fungus at (C) 72 HAI. F, Bar represents100 $\mu \mathrm{m}$. a, appressorium; cc, cortical cell layers; ec, epidermal cell layers; fc, fungal colonization; ih; infection hypha, s, spore. 
Mullet 1997) and in activating genes for plant disease resistance (Johnson et al. 1989; Xu et al. 1994; Reinbothe et al. 1994). However, the role of JA during fruit ripening has not been well studied, in contrast to the role of ethylene (Theologis 1992). A few cases in which methyl JA triggers the ripening process of climacteric fruits including tomato and apple with ethylene production were reported (Czapski and Saniewski 1992; Saniewski et al. 1987a, 1987b). However, the role of JA in nonclimacteric fruits such as pepper, grape, and strawberry has not been reported.

Fruit ripening represents a genetically synchronized developmental process unique to plants (Giovannoni 1993). Generally, ripe fruit is accompanied by an increased susceptibility to pathogen infection (Prusky et al. 1991; Swinburne 1983). As one of the reproductive organs of the plants, the fruit must be protected from pathogens or abiotic stresses. Pathogenesisrelated (PR) proteins and several antifungal proteins that are responsible for protection against pathogens during fruit ripening have been identified (Fils-Lycaon et al. 1996; Meyer et al. 1996; Salzman et al. 1998; Tattersall et al. 1997). In the present study, the expression of the PepCYP gene was detected only in the ripe fruit after fungal inoculation or wounding. We propose that the PepCYP gene is involved in the defense mechanism for the ripe fruit in order to maintain fruit integrity and to protect seed maturation against biotic and abiotic stresses.

Initial and mature infection hypha of $C$. gloeosporioides developed on pepper fruits at 12 and 24 HAIs, respectively (Oh et al. 1998). PepCYP mRNA in the fruit started to accumulate from $12 \mathrm{HAI}$ and increased at $24 \mathrm{HAI}$ (Fig. 4). Thus, it is likely that PepCYP gene expression occurs when the fungus directly invades the fruit by infection hypha. In microscopic and in situ hybridization observations, although cells didn't directly contact the fungus, the induction of PepCYP transcript was detected throughout the epidermal cell layers. This result suggests that transcripts are induced by plant-derived defense signals generated after the fungus invasion. On the other hand, the accumulation of $P R-2$ mRNA in the ripe fruit at $3 \mathrm{HAI}$ when the fungus germinates suggests that this gene is induced early in the incompatible interaction by fungal elicitors rather than plantderived signals. The induction of $P e p C Y P$ and $P R-2$ mRNAs was observed to be higher and faster, respectively, in the incompatible interaction than in the compatible interaction. Similar phenomena have been reported for many other plant-pathogen interactions (Ebrahim-Nesbat et al. 1989, 1993). Thus, higher and faster expression of many defense genes including $P e p C Y P$ and $P R-2$ may confer disease resistance for the ripe fruit against fungal infection.

In summary, the present study showed that active fungal invasion and colonization processes are suppressed in the incompatible-interacting ripe fruit. Notably, PepCYP mRNA accumulated to higher levels in the ripe fruit in response to the fungal infection. The transcript is mainly localized in the epidermal cell layers of the pepper fruit after the fungal inoculation. We suggest that the PepCYP gene product plays a critical role in the plant's defense mechanism against the fungal invasion and colonization of the epidermal cells of the fruit in the incompatible interaction. It remains to be elucidated how the cytochrome $\mathrm{P} 450$ protein provides an effective defense against fungal infection in pepper.

\section{MATERIALS AND METHODS}

\section{Fungal inoculum and plant material.}

Monoconidial isolate KG13 of C. gloeosporioides was cultured on potato dextrose agar (Difco, Detroit, MI) for 5 days in darkness at $28^{\circ} \mathrm{C}$. Sterile, distilled water was added and conidia were harvested through four layers of cheesecloth to remove mycelial debris. Ten microliters of $5 \times 10^{5}$ conidia of $C$. gloeosporioides per $\mathrm{ml}$ was used for drop inoculation on both ripe and unripe pepper fruits as described (Oh et al. 1998).

Both ripe-red and unripe-mature-green fruits of pepper cv. Nokkwang were grown and harvested under greenhouse conditions. For wound treatments, five healthy ripe and unripe fruits were deeply scratched with a knife and incubated at $100 \%$ relative humidity at $27^{\circ} \mathrm{C}$ in the dark. Ten microliters of $\mathrm{ABA}$ at 4 and $40 \mu \mathrm{M}$, or JA at 4 and $40 \mu \mathrm{M}$ were drop-applied to both ripe and unripe sets of five fruits, respectively. After incubation under the conditions described above, the fruits were excised to $1 \mathrm{~cm}^{2}$ at the drop-application site for the fungus, ABA or JA, and at the wounding site. The samples were then frozen in liquid nitrogen. Leaf, root, and stem samples were harvested from 3-week-old plants and handled as described above for fungal inoculation and wounding.

\section{mRNA differential display.}

Total RNA was extracted from healthy or infected ripe and unripe fruits with the RNeasy Plant kit (Qiagen, Hilden, Germany) according to the manufacturer's instructions. We used total RNA as template for the reverse transcriptase reaction and performed differential display with $\left[\alpha^{33} \mathrm{P}\right] \mathrm{dATP}$ instead of $\left[\alpha^{35}\right.$ S $]$ dATP (Liang and Pardee 1992). Anchored primers and random-arbitrary primers were purchased from Operon Technologies (Operon, Alameda, CA). Polymerase chain reaction (PCR)-amplified cDNA fragments were separated on denaturing $5 \%$ polyacrylamide gels in Tris-borate buffer. cDNAs were recovered from the gel, amplified by PCR, and cloned into pGEM-T easy vector (Promega, Madison, WI) as described (Oh et al. 1995).

\section{Construction and screening of cDNA library.}

Poly $(\mathrm{A})^{+}$mRNA was purified from total RNA of unripegreen fruits at 24 and $48 \mathrm{~h}$ after inoculation with C. gloeosporioides with the Oligotex mRNA Kit (Qiagen). The cDNA library $\left(2.5 \times 10^{5}\right.$ PFUs with a mean insert size of $\left.1.2 \mathrm{~kb}\right)$ was constructed in the cloning vector $\lambda$ ZAPII (Stratagene, Heidelburg, Germany) according to the manufacturer's instructions.

A partial cDNA, designated pddICC6, from the differential display analysis was used as a probe to screen the $C$. gloeosporioides-induced pepper cDNA library. After three rounds of plaque hybridization, positive plaques were purified. The pBluescript SK phagemid containing cDNAs was excised in vivo from the ZAP Express vector with the ExAssit helper phage.

\section{DNA sequencing and homology search.}

cDNA sequencing was performed with an ALFexpress automated DNA sequencer (Amersham Pharmacia Biotech, Buckinghamshire, UK). Analysis of nucleotide and amino acid sequences was performed with the DNASIS sequence analysis software for Windows, version 2.1 (Hitachi, San Bruno, CA). The multiple sequence alignment was produced 
with the Clustal W program. For a homology search, cDNA sequence was compared with the NCBI nonredundant data bases, using the BLAST electronic mail server (Altschul et al. 1997).

\section{RNA blot and hybridization.}

Total RNA (10 $\mu \mathrm{g}$ per lane) from each plant tissue used in this study was separated on $1.2 \%$ denaturing agarose gels in the presence of formaldehyde. RNA gel blotting, hybridization, and washing were conducted as described by the manufacturer of the positively charged nylon membrane employed (Hybond $\mathrm{N}^{+}$; Amersham Pharmacia Biotech). Radiolabeled probes were prepared with $\left[\alpha^{32} \mathrm{P}\right] \mathrm{dCTP}$ (Amersham Pharmacia Biotech), using a random primer labeling kit (Boehringer, Mannheim, Germany).

\section{Tissue preparation and in situ hybridization.}

Pepper fruits were fixed in $1 \%$ glutaraldehyde/2\% paraformaldehyde in $100 \mathrm{mM}$ sodium phosphate buffer $\mathrm{pH}$ 7.0, dehydrated in ethanol, and embedded in paraffin. Tissues were transverse-sectioned at $10 \mu \mathrm{m}$ in thickness and stained with $4^{\prime}$ 6-diamidino-2-phenylindole (DAPI; $10 \mu \mathrm{g} / \mathrm{ml}$ ) to examine the infection hypha of the fungus in pepper fruits (Russell et al. 1975).

pddICC6 was used to prepare gene-specific digoxigenin (DIG)-labeled, antisense RNA probes with T7 RNA polymerase or sense RNA probes, using sp6 RNA polymerase. Hybridization steps were performed according to the manufacturer's recommendation (Boehringer).

\section{ACKNOWLEDGMENTS}

We would like to thank In Seok Oh for providing the isolates of $\mathrm{Col}$ letotrichum gloeosporioides, Doil Choi for providing a cDNA for the PR-2 gene, and Jung Mook Kim for helpful discussion and critical reading of the manuscript. KLESL publication no. 31.

\section{LITERATURE CITED}

Adikaram, N. K. B., Brown, A. E., and Swinburne, T. R. 1983. Observations on infection of Capsicum annuum fruit by Glomerella cingulata and Colletotrichum capsici. Trans. Brit. Mycol. Soc. 80:395-401.

Altschul, S. F., Madden, T. L., Schäffer, A. A., Zhang, J., Zhang, Z., Miller, W., and Lipman, D. J. 1997. Gapped BLAST and PSI-BLAST: A new generation of protein database search programs. Nucleic Acids Res. 25:3389-3402.

Back, K., He, S., Kim, K. U., and Shin, D. H. 1998. Cloning and bacterial expression of sesquiterpene cyclase, a key branch point enzyme for the synthesis of sesquiterpenoid phytoalexin capsidiol in UV-challenged leaves of Capsicum annuum. Plant Cell Physiol. 39:899-904.

Bailey, J. A., O'Connell, R. J., Pring, R. J., and Nash, C. 1992. Infection strategies of Colletotrichum species. Pages 88-120 in: Colletotrichum: Biology, Pathology and Control. J. A. Bailey and J. A. Jeger, eds. CAB Int., Wallingford, UK.

Batard, Y., Schalk, M., Pierrel, M. A., Zimmerlin, A., Durst, F., and Werck-Reichhart, D. 1997. Regulation of the cinnamate 4-hydroxylase (CYP73a1) in Jerusalem artichoke tubers in response to wounding and chemical treatments. Plant Physiol. 113:951-959.

Bozak, K. R., Yu, H., Sireväg, R., and Christoffersen, R. E. 1990. Sequence analysis of ripening-related cytochrome P-450 cDNAs from avocado fruit. Proc. Natl. Acad. Sci. USA 87:3904-3908.

Chavez-Moctezuma, M. P., and Lozoya-Gloria, E. 1996. Biosynthesis of the sesquiterpene phytoalexin capsidiol in elicited root cultures of chili pepper (Capsicum annuum). Plant Cell Rep. 15:360-366.

Christoffersen, R. E., Percival, F. W., and Bozak, K. 1995. Functional and DNA sequence divergence of the CYP71 gene family in higher plants. Pages 207-219 in: Drug Metabolism and Drug Interactions. F. Durst and D. P. O'Keefe, eds. Freund, UK.

Clark, I. M., Forde, B. G., and Hallahan, D. L. 1997. Spatially distinct expression of two new cytochrome P450s in leaves of Nepeta racemosa: Identification of a trichome-specific isoform. Plant Mol. Biol. 33:875-885.

Creelman, R. A., and Mullet, J. E. 1997. Biosynthesis and action of jasmonates in plants. Annu. Rev. Plant Physiol. Plant Mol. Biol. 48:355381.

Creelman, R. A., Tierney, M. L., and Mullet, J.E. 1992. Jasmonic acid/ methyl jasmonate accumulate in wounded soybean hypocotyls and modulate wound gene expression. Proc. Natl. Acad. Sci. USA 89: 4938-4941.

Czapski, J., and Saniewski, M. 1992. Stimulation of ethylene production and ethylene-forming enzyme in fruits of the non-ripening nor and rin tomato mutants by methyl jasmonate. J. Plant Physiol. 139:265-268.

Czernic, P., Huang, H. C., and Marco, Y. 1996. Characterization of $h s r 201$ and $h s r 515$, two tobacco genes preferentially expressed during the hypersensitive reaction provoked by phytopathogenic bacteria. Plant Mol. Biol. 31:255-265.

Daykin, M. E. 1984. Infection of blueberry fruit by Colletotrichum gloeosporioides. Plant Dis. 68:948-950.

Dodd, J. C., Estrada, A., Matcham, A., Jeffries, P., and Jeger, M. J. 1991. The effect of environmental factors on Colletotrichum gloeosporioides, the causal agent of mango anthracnose, in the Philippines. Plant Pathol. 40:568-575.

Ebrahim-Nesbat, F., Behnke, S., Kleinhofs, A., and Apel, K. 1989. Cultivar-related differences in the distribution of cell-wall bound thionins in compatible and incompatible interactions between barley and powdery mildew. Planta 179:203-210.

Ebrahim-Nesbat, F., Bohl, S., Heitefuss, R., and Apel, K. 1993. Thionin in cell walls and papillae of barley in compatible and incompatible interactions with Erysiphe graminis f. sp. hordei. Physiol. Mol. Plant Pathol. 43:343-352.

Fils-Lycaon, B. R., Wiersma, P. A., Eastwell, K. C., and Sautiere, P. 1996. A cherry protein and its gene, abundantly expressed in ripening fruit, have been identified as thaumatin-like. Plant Physiol. 111:269273.

Frank, M. R., Deyneka, J. M., and Schuler, M. A. 1996. Cloning of wound-induced cytochrome P450 monooxygenase expressed in pea. Plant Physiol. 110:1035-1046.

Frey, M., Kliem, R., Saedler, H., and Gierl, A. 1995. Expression of a cytochrome P450 gene family in maize. Mol. Gen. Genet. 246:100109.

Giovannoni, J. J. 1993. Molecular biology of fruit developmental and ripening. Pages 253-287 in: Methods in Plant Molecular Biology. J. Bryant, ed. Academic Press, New York.

Hutvágner, G., Barta, E., and Banfalvi, Z. 1997. Isolation of sequence analysis of a cDNA and related gene for cytochrome $\mathrm{P} 450$ proteins from Solanum chacoense. Gene188:247-252.

Hwang, C.-S., and Kolattukudy, P. E. 1995. Isolation and characterization of genes expressed uniquely during appressorium formation by Colletotrichum gloeosporioides conidia induced by the host surface wax. Mol. Gen. Genet. 247:282-294.

Johnson, R., Narváez, J., An, G., and Ryan, C. 1989. Expression of proteinase inhibitors I and II in transgenic tobacco plants: Effects on natural defense against Manduca sexta larvae. Proc. Natl. Acad. Sci. USA 86:9871-9875.

Kessmann, H., Choudhary, A. D., and Dixon, R. A. 1990. Stress response in alfalfa (Medicago sativa L.). III. Induction of medicarpin and cytochrome P450 enzyme activities in elicitor-treated cell suspension cultures and protoplasts. Plant Cell Rep. 9:38-41.

Kim, K. D., Oh, B. J., and Yang, J. 1999. Differential interactions of a Colletotrichum gloeosporioides isolate with green and red pepper fruits. Phytoparasitica 27:1-10.

Kim, W. G., Cho, E. K., and Lee, E. J. 1986. Two strains of Colletotrichum gloeosporioides Penz. causing anthracnose on pepper fruits. Korean J. Plant Pathol. 2:107-113.

Liang, P., and Pardee, A. B. 1992. Differential display of eukaryotic messenger RNA by means of the polymerase chain reaction. Science 257:967-971.

Manandhar, J. B., Hartman, G. L., and Wang, T. C. 1995. Conidial germination and appressorial formation of Colletotrichum capsici and C. gloeosporioides isolates from pepper. Plant Dis. 79:361-366. 
Maule, A. J., and Ride, J. P. 1983. Cinnamate 4-hydroxylase and hydroxycinnamate: CoA ligase in wheat leaves infected with Botrytis cinereae. Phytochemistry 22:1113-1116.

Meyer, B., Houlné, G., Pozueta-Romero, J., Schantz, M.-L., and Schantz, R. 1996. Fruit-specific expression of a defensin-type gene family in bell pepper. Upregulation during ripening and upon wounding. Plant Physiol. 112:615-622.

Mizutani, M., Ward, E., and Ohta, D. 1998. Cytochrome P450 superfamily in Arabidopsis thaliana: Isolation of cDNAs, differential expression, and RFLP mapping of multiple cytochromes P450. Plant Mol. Biol. 37:39-52.

Nebert, D. W., Ride, J. P., Coon, M. J., Estabrook, R. W., Feyereisen, R., Fuji-Kuriyama, Y., Gonzales, F. J., Guenguerich F. P., Gunsalus, I. C., Johnson, E. F., Loper, J. C., Sato, R., Waterman, M. R., and Waxman D. J. 1991. The P450 superfamily: Update on new sequences, gene mapping, and recommended nomenclature. DNA Cell Biol. 10:1-14.

Oh, B. J., Balint, D. E., and Giovannoni, J. J. 1995. A modified procedure for PCR-based differential display and demonstration of use in plants for isolation of gene related to fruit ripening. Plant Mol. Biol. Rep. 13:70-81.

Oh, B. J., Kim, K. D., and Kim, Y. S. 1998. A microscopic characterization of the infection of green and red pepper fruits by an isolate of Colletotrichum gloeosporioides. J. Phytopathol. 146:301-303.

Peña-Cortés, H., Prat, S., Atzorn, R., Wasternack, C., and Willmitzer, L. 1996. Abscisic acid-deficient plants do not accumulate proteinase inhibitor II following systemin treatment. Planta 198:447-451.

Podila, G. K., Rogers, L. M., and Kolattukudy, P. E. 1993. Chemical signals from avocado surface wax trigger germination and appressorium formation in Colletotrichum gloeosporioides. Plant Physiol. 103: 267-272.

Prusky, D., Plumbley, R. A., and Kobiler, I. 1991. The relationship between the antifungal diene levels and fungal inhibition during quiescent infections of Colletotrichum gloeosporioides in unripe avocado fruits. Plant Pathol. 40:45-52.

Prusky, D., and Saka, H. 1989. The role of epicuticular wax of avocado fruit in appressoria formation of Colletotrichum gloeosporioides. Phytoparasitica 17:140.

Reinbothe, S., Reinbothe, C., Lehman, J., Becker, W., Apel, K., and Parthier, B. 1994. JIP60, a methyl jasmonate-induced ribosomeinactivating protein involved in plant stress reactions. Proc. Natl. Acad. Sci. USA 91:7012-7016.
Russell, W. C., Newman, C., and Williamson, D. H. 1975. A simple cytochemical technique for demonstration of DNA in cells infected with mycoplasmas and viruses. Nature 253:461-462.

Salzman, R. A., Tikhonova, I., Bordelon, B. P., Hasegawa, P. M., and Bressan, R. A. 1998. Coordinate accumulation of antifungal proteins and hexoses constitutes a developmentally controlled defense response during fruit ripening in grape. Plant Physiol. 117:465-472.

Saniewski, M., Czapski, J., Nowacki, J., and Lange, E. 1987a. The effect of methyl jasmonate on ethylene and 1-amino-cyclopropane-1-carboxylic acid production in apple fruits. Biol. Plant 29:199-203.

Saniewski, M., Nowacki, J., and Czapski, J. 1987b. The effect of methyl jasmonate on ethylene production and ethylene-forming enzyme activity in tomatoes. J. Plant Physiol. 129:175-180.

Schopfer, C. R., and Ebel, J. 1998. Identification of elicitor-induced cytochrome P450s of soybean (Glycine $\max$ L.) using differential display of mRNA. Mol. Gen. Genet. 258:315-322.

Staples, R. C., and Macko, V. 1980. Formation of infection structures as a recognition response in fungi. Exp. Mycol. 4:2-16.

Swinburne, T. R. 1976. Stimulants of germination and appressoria formation by Colletotrichum musae (Berk. \& Curt.) Arx. in banana leachate. Phytopathol. Z. 87:74-90.

Swinburne, T. R. 1983. Post-Harvest Pathology of Fruits and Vegetables. Academic Press, New York.

Tattersall, D. B., van Heeswijck, R., and Bordier, H. P. 1997. Identification and characterization of a fruit-specific, thaumatin-like protein that accumulates at very high levels in conjunction with the onset of sugar accumulation and berry softening in grapes. Plant Physiol. 114: 759-769.

Theologis, A. 1992. One rotten apple spoils the whole bushel: The role of ethylene in fruit ripening. Cell 70:181-184.

Ward, E. W. B. 1976. Capsidiol production in pepper leaves in incompatible interactions with fungi. Phytopathology 66:175-176.

Wasternack, C., and Partheir, B. 1997. Jasmonate-signaled plant gene expression. Trends Plant Sci. 2:302-307.

Watson, D. G., and Brooks, C. J. 1984. Formation of capsidiol in Capsicum annuиm fruits in response to non-specific elicitors. Physiol. Plant Pathol. 24:331-337.

Xu, Y., Chang, P.-F. L., Liu, D., Narasimhan, M. L., Raghothama, K. G., Hasegawa, P. M., and Bressan, R. A. 1994. Plant defense genes are synergistically induced by ethylene and methyl jasmonate. Plant Cell 6:1077-1085 